\title{
Lined waste containment systems: a method for design and performance evaluation
}

\author{
H. Akgün
}

\begin{abstract}
The objective in designing lining systems for the containment of the leachate generated within a landfill is the prevention of contamination of groundwater and surface waters. The technology involving the design of these systems has progressed to a point that the integrity of the containment can be relied on over the long term. Double-lined systems provide the additional benefit of being able to quantify the performance of the lining system through the detection of leakage through the upper liner. The difficulty, however, lies with the qualitative evaluation of the system. This paper addresses this issue and offers a practical approach for the design and evaluation of double-lined systems and the leakage that is detected.
\end{abstract}

Key words Containment system - Landfill · Leachate $\cdot$ Leakage

\section{Introduction}

Clay, or other low-permeability soil-lined ponds, surface impoundments and sanitary landfills have been traditionally constructed for the containment of liquids, sludges and leachate-generating solids for many decades. However, for the past several decades, but in particular in the 1980s, the use of polymeric materials (geomembranes) has become routinely adopted in most parts of North America, both as a single liner and also in composite construction with the traditional clay soils.

One of the benefits that has been realized from the incorporation of geomembrane liners is the ability to obtain rapid leak detection in double-lined systems. In many double-lined structures, the rapid detection of a leak can allow sufficient time for repair or remediation

Received: 16 February 1996 - Accepted: 29 May 1996

H. Akgün (ه)

Department of Geological Engineering, Middle East Technical University, Ankara 06531, Turkey before there is any opportunity for the leakage to exit the containment system.

\section{Lining systems}

Regardless of the nature of the structure or its contents, the purpose of the lining system is containment of leachate. With landfill leachates, ponds and surface impoundments containing liquids which would have deleterious effects on the surrounding environment, doublelining systems have been developed, which have the dual function of intercepting leakage which occurs through the top liner, as well as controlling the driving forces to a second liner to the extent that virtual certainty of no leakage through the bottom liner can be achieved.

Figure 1 illustrates a variety of lining system configurations commonly constructed. These six variations fall into three groups: single liners, double liners and composite liners. A double-lining system is created with the addition of a second liner. It consists of two liners and an intermediate drainage layer. This intermediate drainage layer is depicted as a granular soil but, in fact, can be comprised of a variety of drainage media, including geosynthetic materials such as geonets in addition to granular soils.

Any of the six lining configurations listed in Figure 1 may also contain leachate collection systems (comprised of granular soils or geosynthetic materials) over the topmost (primary) liners. The leachate collection system removes leachate to a sump through some form of collection system in order to reduce the leachate head.

The single liner has all but disappeared as a viable option for the containment of liquids and wastes in the United States, not because of any particular shortcoming on the part of clay-only or geomembrane-only liners, but because it has been clearly demonstrated through considerable research, primarily in the United States (e.g. by Bonaparte and others 1989; Giroud and Bonaparte $1989 \mathrm{a}, \mathrm{b})$ that a single composite liner composed of both geomembrane and clay performs in a superior manner to either alone.

Regardless of the configuration of the lining system, the primary concern in the design is the magnitude of leakage through the top liner of a double-lined system, and through the liner in a single-lined system. 

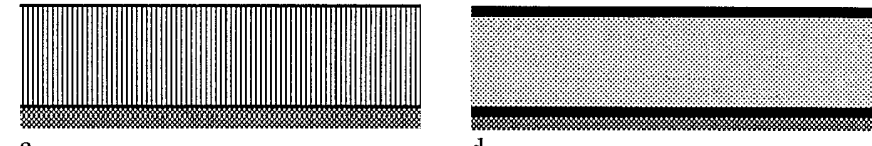

d

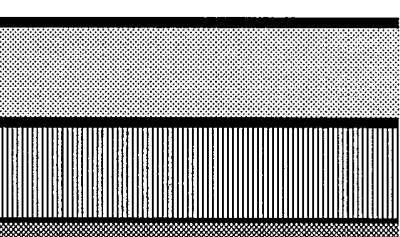

b

e
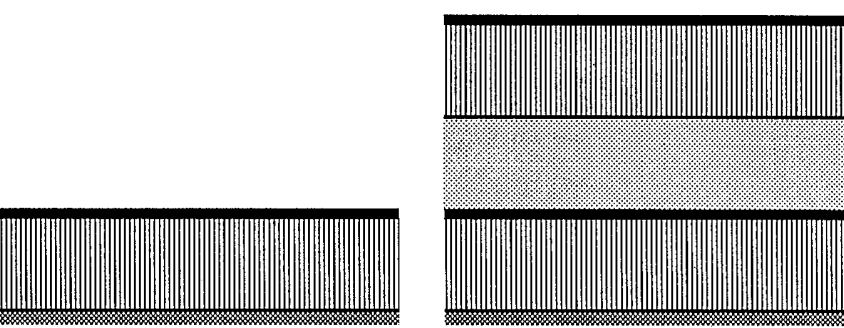

\section{Geomembrane}
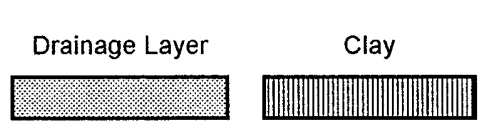

Subgrade

Fig. 1a-f

Types of lining systems: a single clay-only liner, b single geomembrane-only liner, c single geomembrane/clay composite liner, d double geomembrane-only liner, e double liner with geomembrane-only top liner and geomembrane/clay composite bottom liner, and f double composite liner with

geomembrane/clay composite top and bottom liners

\section{Leakage through liners}

\section{Calculation of leakage}

It is necessary to calculate the expected leakage through a clay-only, geomembrane-only or clay/geomembrane composite liner in order to evaluate the performance of the system. These calculations have been clearly documented and presented elsewhere (e.g. Bonaparte and others 1989; Giroud and Bonaparte 1989a,b).

These equations are repeated herein for the purpose of reference. However, the theory and explanation accompanying them is paramount to their use and the original references are essential to a design application.

The mechanism of leakage through a clay-only liner is assumed herein to be only due to fluid permeation. However, it has been thoroughly documented over the years (e.g. by Lambe 1958; Mitchell and others 1965) that there are numerous parameters which affect the structure of a clay liner. For example, freeze/thaw and wet/dry cycles can lead to the build-up of a secondary structure within the clay. These in turn can create preferential flow paths either, directly causing or abetting leakage, despite the healing of cracks upon wetting. Leakage due to these preferential flow paths is not considered in this paper.
Leakage due to fluid permeation through a clay-only liner can be calculated from Darcy's law as follows:

$\mathrm{Q}_{\mathrm{s}}=\mathrm{k}_{\mathrm{s}} \frac{\mathrm{h}}{\mathrm{H}_{\mathrm{S}}} \mathrm{A}$,

where $Q_{s}$ is the leakage rate through the clay (soil) liner $\left(\mathrm{m}^{3} / \mathrm{s}\right) ; k_{\mathrm{s}}$ is the hydraulic conductivity of clay $(\mathrm{m} / \mathrm{s}) ; h$ is the leachate head acting on top of the liner (m); $H_{s}$ is the thickness of the clay liner (m); and $A$ is the area of the liner considered $\left(\mathrm{m}^{2}\right)$.

The leachate (hydraulic) head in Eq. 1 is assumed to be equal to the depth of leachate on top of the liner. This is a valid assumption only when the leachate (liquid) on top of the liner is not flowing, with the exception of slow movement due to leakage through the liner. This assumption will also be utilized in the subsequent equations related to leakage rate calculations. Eq. 1 further assumes that: (1) the clay component of the liner is intact, e.g. there is no pre-existing hole or other preferential flow path through which the leachate migrates; (2) steady-state flow conditions exist; (3) the flow through the liner is vertical and hence, for simplicity, each case assumes a horizontal liner.

The two mechanisms of leakage through geomembrane-only and geomembrane/clay composite liners are due to fluid permeation and flow through holes in the geomembrane. Akgün and Wallace (1993) have shown that leakage rates due to fluid permeation through these liners is not very significant and are about one to four orders of magnitude lower than the leakage rates caused by the defects in the geomembrane. For these reasons, leakage due to fluid permeation through geomembraneonly and composite liners are not considered in this paper (i.e. leakage only due to defects in the geomembranes are considered).

From Bonaparte and others (1989), the expected leakage rate through holes in a geomembrane-only liner can be calculated from Bernoulli's equation for free flow through an orifice in a geomembrane that is assumed to be located between two infinitely porous media using Eq. 2:

$\mathrm{Q}_{\mathrm{G}}=\mathrm{nC}_{\mathrm{B}} \mathrm{a}(2 \mathrm{gh})^{0.5}$,

where $Q_{\mathrm{G}}$ is the expected leakage rate through holes in a geomembrane $\left(\mathrm{m}^{3} / \mathrm{s}\right) ; n$ is the number of holes in the geomembrane; $C_{B}$ is a dimensionless coefficient dependent on the shape of the orifice, assumed equal to $0.6 ; a$ is the area of the hole $\left(\mathrm{m}^{2}\right) ; g$ is the acceleration due to gravity $\left(\mathrm{m} / \mathrm{s}^{2}\right)$; and $h$ is the leachate head acting on top of the liner $(\mathrm{m})$.

For the case of a geomembrane/clay composite liner with very good contact (Bonaparte and others 1989), the expected leakage rate through holes in the geomembrane above an intact clay liner can be empirically expressed by Eq. 3:

$\mathrm{Q}_{\mathrm{C}}=0.21 \mathrm{na}^{0.1} \mathrm{~h}^{0.9} \mathrm{k}_{\mathrm{S}} 0.74$

where $Q_{\mathrm{C}}$ is the expected leakage rate through holes in the geomembrane component of a geomembrane/clay 
composite liner $\left(\mathrm{m}^{3} / \mathrm{s}\right) ; k_{\mathrm{s}}$ is the hydraulic conductivity of clay $(\mathrm{m} / \mathrm{s}) ; n, a$ and $h$ are as defined in Eq. 2 .

To allow comparison of the results of leakage through a clay-only liner to the leakage through a hole in the geomembrane of a geomembrane-only or geomembrane/ clay composite liner, a frequency of ten holes per hectare (or one hole per $1000 \mathrm{~m}^{2}$ ) is assumed (i.e. $n=1 / 1000 \mathrm{~m}^{2}$ ), each having a diameter equal to the thickness of the geomembrane, herein taken as $2 \mathrm{~mm}$. This leads to a selection of a unitized leakage rate, which is defined as the leakage through a given area, herein taken as $1000 \mathrm{~m}^{2}$, and expressed as $\mathrm{m}^{3} / \mathrm{s} / 1000 \mathrm{~m}^{2}$. This unitized leakage rate, $q$, is given by Eq. 4 :

$q=Q$ for $A=1000 \mathrm{~m}^{2} ; n=1 / 1000 \mathrm{~m}^{2}$.

The unitized leakage rate results for a $1.0-\mathrm{m}$-thick clay liner with a hydraulic conductivity of $1.0 \times 10^{-9} \mathrm{~m} / \mathrm{s}$, subjected to leachate heads of $1 \mathrm{~m}, 0.1 \mathrm{~m}$, and $0.01 \mathrm{~m}$ are illustrated in Table 1. This covers the spectrum of likely possibilities above the clay liner in a landfill with different configurations of leachate collection layers. Table 1 also shows that the leakage rates through clay-only or geomembrane-only liners can be reduced by two to three orders of magnitude by the use of a composite liner. The parameters have been selected to illustrate that composite liners perform in a superior manner to either of the clayonly or geomembrane-only options.

Table 1

Unitized expected leakage rates $\left(\mathrm{q} ; \mathrm{m}^{3} / \mathrm{s} / 1000 \mathrm{~m}^{2}\right)$

\begin{tabular}{|c|c|c|c|c|}
\hline \multirow{2}{*}{$\begin{array}{l}\text { Liner } \\
\text { type }\end{array}$} & \multirow{2}{*}{$\begin{array}{l}\text { Liner } \\
\text { thickness } \\
(\mathrm{m})\end{array}$} & \multicolumn{3}{|c|}{ Leachate head (m) } \\
\hline & & 0.01 & 0.1 & 1.0 \\
\hline $\begin{array}{l}\text { Clay-only } \\
\text { (Eqs. 1, 4) }\end{array}$ & 1.000 & $1.0 \times 10^{-8}$ & $1.0 \times 10^{-7}$ & $1.0 \times 10^{-6}$ \\
\hline $\begin{array}{l}\text { Geomembrane-only } \\
\text { (Eqs. 2, 4) }\end{array}$ & 0.002 & $8.4 \times 10^{-7}$ & $2.6 \times 10^{-6}$ & $8.4 \times 10^{-6}$ \\
\hline $\begin{array}{l}\text { Geomembrane/clay } \\
\text { composite } \\
\text { (Eqs. } 3,4)\end{array}$ & 1.002 & $2.1 \times 10^{-10}$ & $1.6 \times 10^{-9}$ & $1.3 \times 10^{-8}$ \\
\hline
\end{tabular}

\section{Expected leakage}

During the design process, calculation of the leakage that would normally be expected for the particular parameters and configuration provides us with the expected leakage for the structure. This quantity is based on some empirical factors, such as the size and frequency of holes, expected leachate head, constant leachate head over time and rapid leak detection. This expected leakage is considered to be the leakage that should normally be expected to penetrate the top liner of a double-lined system. It is based on the assumptions of good design, good installation practices, and high-quality construction quality assurance (CQA). The calculation of expected leakage is based on the assumption that, having satisfied all other assumptions regarding quality standards, there will still be ten holes per hectare of liner.
To determine the expected leakage through a geomembrane-only or geomembrane/clay composite liner, Bonaparte and others (1989) suggest the use of a hole area of $100 \mathrm{~mm}^{2}$ in whichever of Eq. 2 or 3 above applies. The assumption of ten holes per hectare is then applied to the total area of the landfill. It is believed that this is misrepresentative of the landfill cell for a variety of reasons:

1. Leachate head (or head of liquid regardless of its nature) is a time function. The source of this leachate is precipitation onto the landfill cell. In an unlikely sequence of precipitation equalling collection within the system, the head could be maintained at a uniform level. Realistically, however, if a relatively high-capacity leachate collection system has been designed (one of the design criteria), then, except during periods of intense rainfall, the level of head would only be at its peak for a relative "instant" and, in fact, the head could be represented by some decreasing time function, at least after the precipitation stops. The assumed maximum of expected head would therefore be a peak value. In order to accurately depict the varying head during that period, a time function would have to be employed. The use of the maximum head to determine the leakage and extrapolate it through time could grossly exaggerate the expected leakage quantity for the particular hole modeled.

2. The hole area of $100 \mathrm{~mm}^{2}$ suggested by Bonaparte and others (1989) for determining the leakage is considered by the author to be very large. This belief is predicated upon the fact that one of the assumptions employed in the expected leakage calculation is the utilization of high-quality construction quality assurance (CQA). From the author's experiences in providing CQA services mostly for high-density polyethylene (HDPE) liners, the probability of holes of that magnitude escaping testing in the CQA operations is believed to be minimal, all the more so at the prescribed frequency. Excessive leakage due to liner damage (for example, a large tear in the liner) or other gross flaw may be attributed to the lack of, or to substandard CQA services through the construction of the lining system, which is a violation of one of the primary assumptions prerequisite to the premise.

The result of these calculations is, therefore, a number which is representative of the worst case. This "worst case number" does not really serve as a warning for the type of problem that is intended. It does, however, serve as a forewarning of the problems in the before-commissioning stage in that gross leakage through a large tear can be found prior to the use of the landfill.

The concept of expected leakage is, however, important during the design stage in the form of providing the design engineer with a benchmark quantity which cannot be tolerated, and hence with an understanding of the standards which must be applied. It does not, however, provide a benchmark for determining the performance of the lining system, which is just as important during design as it is during operations and beyond. The author 
proposes a different approach which, although not an absolute solution, provides a means of comparing the performance of a lining system and, in fact, can allow a sensitivity analysis during design to optimize that (expected) performance.

\section{Leachate collection}

The primary driving force through any liner which results in leakage through a hole is the leachate head acting directly on the liner. The magnitude of this parameter is a function of the precipitation quantities and intensities and the ability of the leachate collection system to remove the leachate from the system. The minimization of the leachate head is dependent on the efficient removal of the leachate to a sump through some form of collection system. The transmissivity of the leachate collection layer is given by

$\mathrm{T}=\mathrm{kt}$,

where $T$ is the transmissivity of the leachate collection layer $\left(\mathrm{m}^{2} / \mathrm{s}\right) ; k$ is the hydraulic conductivity of the leachate collection layer $(\mathrm{m} / \mathrm{s})$; and $t$ is the leachate collection layer thickness $(\mathrm{m})$.

The higher the transmissivity, the greater the quantity of leachate that can be removed from above the liner. Consequently, the design of the leachate collection system is paramount to the performance of the system. Any modifications which can be made to increase the efficiency of the leachate collection system will result in lower leakage.

\section{Leachate collection efficiency}

During the design process for a double-lined system, the two primary calculations made are those of leakage quantity and leachate removal. These are the two parameters that can be measured during operations and give the greatest opportunity for a quantitative assessment of the performance of the system. As a result, the efficiency of the leachate collection system is important for the determination of the maximum values of the parameters which, in the presence of a hole, will cause leakage.

The actual quantity of leakage, both as expected and as measured, will vary inconsistently from one geometry to another. Rather than to allow the geometry of a landfill cell to dictate the anticipated results, however, it is more pragmatic to allow the desired results to dictate the geometry. Consequently, it is proposed that a more practical and verifiable parameter should be introduced into the design process. This quantity is the Leakage Ratio (LR), which is defined as the ratio of the leachate quantity to the leakage quantity:

$\mathrm{LR}=Q_{\mathrm{LC}} / Q_{\mathrm{LK}}$ where $L R$ is the Leakage Ratio (dimensionless); $Q_{\mathrm{LC}}$ is the quantity of leachate $\left(\mathrm{m}^{3} / \mathrm{s}\right)$; and $Q_{\mathrm{LK}}$ is the quantity of leakage $\left(\mathrm{m}^{3} / \mathrm{s}\right)$.

Both of the flow quantities can be calculated during the design process, based on the analytical procedures described herein and elsewhere. In addition, however, each of these quantities can be measured during the operation of the facility. Hence, a distinction can be made between the design $L R\left(L R_{\text {des }}\right)$ and the actual $L R\left(L R_{\text {meas }}\right)$. This will provide input to not only the evaluation, and the performance of the lining system, but also to the validity of the design assumptions.

\section{Leakage Ratio (LR)}

To illustrate the significance of the $L R$ approach, it is first necessary to calculate the leachate flow, which will represent the quantity of leachate that will seep through a soil drain or flow through a geosynthetic drain above the top liner of a double-lined system:

$Q_{\mathrm{LC}}=\mathrm{TiB}$,

where $Q_{\mathrm{LC}}$ and $T$ are as defined above; $i$ is the liner slope or gradient (dimensionless); and $B$ is the width of the flow path $(\mathrm{m})$.

The leakage rates were previously unitized to units of $\mathrm{m}^{3} / \mathrm{s} / 1000 \mathrm{~m}^{2}$. For the leachate flow, however, this creates a problem, since the areal parameter is not relevant, but rather the width of the flow face. Consequently, for a $1000 \mathrm{~m}^{2}$ area, the flow face could conceivably vary from $1 \mathrm{~m}$ to $1000 \mathrm{~m}$ in width, since the dimensions could be anything provided that they contain an area of $1000 \mathrm{~m}^{2}$. To simplify comparison and the development of the $L R$, it is therefore recommended that a unit width (such as, $B$ $=1 \mathrm{~m}$ ) be used. For the sake of comparison, however, this requires the conversion of the unitized leakage rates to $\mathrm{m}^{3} / \mathrm{s} / \mathrm{m}^{2}$ (Table 2).

Table 2

Unitized expected leakage rates $\left(\mathrm{q} ; \mathrm{m}^{3} / \mathrm{s} / \mathrm{m}^{2}\right)$

\begin{tabular}{|c|c|c|c|c|}
\hline \multirow{2}{*}{$\begin{array}{l}\text { Liner } \\
\text { type }\end{array}$} & \multirow{2}{*}{$\begin{array}{l}\text { Liner } \\
\text { thickness } \\
\text { (m) }\end{array}$} & \multicolumn{3}{|c|}{ Leachate head (m) } \\
\hline & & 0.01 & 0.1 & 1.0 \\
\hline $\begin{array}{l}\text { Clay-only } \\
\text { (Eqs. 1, 4) }\end{array}$ & 1.000 & $1.0 \times 10^{-11}$ & $1.0 \times 10^{-10}$ & $1.0 \times 10^{-9}$ \\
\hline $\begin{array}{l}\text { Geomembrane- } \\
\text { only } \\
\text { (Eqs. 2, 4) }\end{array}$ & 0.002 & $8.4 \times 10^{-10}$ & $2.6 \times 10^{-9}$ & $8.4 \times 10^{-9}$ \\
\hline $\begin{array}{l}\text { Geomembrane/ } \\
\text { clay } \\
\text { composite } \\
\text { (Eqs. } 3,4)\end{array}$ & 1.002 & $2.1 \times 10^{-13}$ & $1.6 \times 10^{-12}$ & $1.3 \times 10^{-11}$ \\
\hline
\end{tabular}

Table 3 has been developed using the leakage rates from Table 2. A liner gradient (slope) of $2 \%$ has been assumed. In each case, a soil drainage layer has been assumed for the leachate collection, $1 \mathrm{~m}$ in thickness, having a hydraulic conductivity of $10^{-4} \mathrm{~m} / \mathrm{s}$. The flow face 
Table 3

Leakage Ratio $\left(L R=Q_{\mathrm{LC}} / Q_{\mathrm{LK}}\right)$

\begin{tabular}{|c|c|c|c|}
\hline \multirow{2}{*}{$\begin{array}{l}\text { Liner } \\
\text { type }\end{array}$} & \multicolumn{3}{|c|}{ Leachate head (m) } \\
\hline & 0.01 & 0.1 & 1.0 \\
\hline Clay-only & $2.0 \times 10^{3}$ & $2.0 \times 10^{3}$ & $2.0 \times 10^{3}$ \\
\hline Geomembrane-only & $2.4 \times 10^{1}$ & $7.6 \times 10^{1}$ & $2.4 \times 10^{2}$ \\
\hline $\begin{array}{l}\text { Geomembrane/clay } \\
\text { composite }\end{array}$ & $9.5 \times 10^{4}$ & $1.3 \times 10^{5}$ & $1.5 \times 10^{5}$ \\
\hline
\end{tabular}

therefore has dimensions of $B \times h$, where $B$ is $1 \mathrm{~m}$ in each case. This leads to quantities of leachate $\left(Q_{\mathrm{LC}}\right)$ for leachate heads $(h)$ of $1 \mathrm{~m}, 0.1 \mathrm{~m}$ and $0.01 \mathrm{~m}$ of $2 \times 10^{-6}$, $2 \times 10^{-7}$ and $2 \times 10^{-8} \mathrm{~m}^{3} / \mathrm{s} / \mathrm{m}^{2}$, respectively (Eq. 7).

Division of these values with the respective unitized leakage rates of Table 2 leads to the results presented in Table 3 .

As can be readily seen, the same relative conclusions can be drawn from these calculations as from those contained in Tables 1 and 2. However, in terms of order of magnitude, the benefits of a composite liner are highlighted even further. In addition, these values can be manipulated by conducting a sensitivity analysis within the parameters of the specific design to determine which factors can be optimized with the greatest result.

The effect of liner gradient is illustrated in Table 4, which presents the variation of $L R$ for a composite liner. In this case, sloping gradients representative of different in-cell conditions for a landfill are input to the calculation of $Q_{\mathrm{LC}}$. These calculations clearly show that, for a given set of parameters, the $L R$ can be maximized for a given increase in liner gradient.

\section{Table 4}

Leakage Ratio $(L R)$ for varying gradients - composite liner

\begin{tabular}{llll}
\hline $\begin{array}{l}\text { Leachate head } \\
(\mathrm{m})\end{array}$ & \multicolumn{3}{c}{ Liner gradient $(i)$} \\
\cline { 2 - 3 } & 0.33 & 0.05 & 0.02 \\
\cline { 4 - 4 } & & $3.9 \times 10^{5}$ & \\
\hline 2.0 & $2.5 \times 10^{6}$ & & $1.5 \times 10^{5}$ \\
0.1 & $1.6 \times 10^{6}$ & $3.1 \times 10^{5}$ & $1.3 \times 10^{5}$ \\
0.01 & $1.6 \times 10^{6}$ & $2.4 \times 10^{5}$ & $9.5 \times 10^{4}$ \\
\hline
\end{tabular}

\section{Design considerations}

The primary purpose of the application of the $L R$ concept to lining design is to determine the effects of the quantity of leachate generated versus the quantity of leakage. In the extreme case, if a given quantity of leakage occurs through the top liner which is well below the expected leakage rate calculated for that liner, it is considered to be performing adequately. If, however, that leakage is a very high proportion of the total leachate quantity, then a serious problem exists. A comparison of the quantity of leakage with the quantity of leachate gener- ated can give a significant identification of liner performance.

Similarly, during design, the use of the leakage quantity expected does not afford the designer a feel for the "rightness" of the result. In fact, for a given liner cross section and leachate head, the same result will always be obtained using the equations presented previously. Geometry will, however, dictate the major input parameter (leachate head) and also the major controlling parameter (drainage from the collection system).

In many cases, the expected leakage rate has been applied as a number that is considered to be the most likely, given the assumptions and parameters that were used in the design. Threshold rates are then established to dictate specific actions that must be taken by the operator when those levels of leakage occur. In the case when actual leakage measured is less than this threshold rate, the numbers do not actually tell the designer or the operator anything about the performance of the cell, other than that it is within the established bounds.

Regardless of the magnitude alone of the leakage, it is important to monitor the performance of the system. The use of the $L R$ provides the ability to do so. Regardless of the fluctuations in the leakage levels, the $L R$ will remain constant (within a tolerable limit) unless the given condition of the cell changes (for example, a tear occurs in the liner).

In Table 3, for a given liner gradient, the $L R$ is shown to be constant even under varying levels of hydraulic head. For example, for the geomembrane/clay composite liner, $L R$ s of $1.5 \times 10^{5}, 1.3 \times 10^{5}$, and $9.5 \times 10^{4}$ are calculated for the parameters selected. Within an orderof-magnitude consideration, it can be concluded that the $L R$ for this liner and conditions is constant at $10^{5}$ for varying levels of threshold head.

Similarly, selecting this particular liner, in Table 4, it is illustrated that, if the liner gradient is varied, different values of $L R$ are obtained, but again for each gradient, a constant value of $L R$ is obtained regardless of the leachate head.

Clearly, in an operating landfill, the gradients are not going to change over time (unless a slide occurs, but that is a different design problem). In fact, the only real variable during operations that is incorporated into these calculations is the hydraulic head, and it can be seen that it does not affect the $L R$. As a result, the $L R$ can be a much greater performance indicator than the absolute magnitude of the leakage quantity alone.

For example, if the leakage flows are plotted over time, there will naturally be significant fluctuations over time consistent with precipitation. For the same period, however, plotting of the $L R$ will yield a constant value (assuming that an allowance of lag time of leakage measurement and leachate measurement has been incorporated into the calculation). The time for concern with the operation of the double-lined system will not be when the leakage rate increases notably, but rather when the $L R$ decreases even slightly. 


\section{Summary and conclusions}

The procedures currently used for the design of doublelining systems include complex equations for the calculation of leakage through the top liners. These procedures could be applied to single-lined systems, but the primary feature of the double liner is the intermediate leakage detection and removal layer, which actually allows the detection of any leakage through the top liner before that leakage has exited the overall system. With a single liner, leakage detection is only possible outside of the lining system, in which case the containment objective has been violated and, in fact, for that reason, leakage quantification may well be impossible.

The currently applied procedures for evaluating the performance of the system are well documented and relevant, provided that the correct parameters are applied. This paper has introduced a modified parameter for the evaluation of leakage through the top liner of a doublelined system, namely the $L R$. In the evaluation of this new parameter, several points can be seen to impact the design process in addition to the evaluative process for these systems.

The use of the $L R$ concept highlights certain design factors, leading to the following conclusions:

1. Although the leachate head is a critical parameter af-

fecting the expected leakage rate through a liner, for a given cell geometry, variations in the leachate head over time do not impact the $L R$. This allows the monitoring program to concentrate on fluctuations in the $L R$, which is much less sensitive to variations in precipitation.

2. The design of the leachate collection system is critical in ensuring that leachate head is minimized throughout the cell. Sizing of all drainage media, including the drainage layers as well as the collection pipes, must be such to allow continuous flow without constriction or backup throughout the system.

3. The $L R$ approach simplifies the monitoring process, as it provides a point of comparison of performance, regardless of the fluctuations in the readings for leachate collection and leakage collection. Initial calibration of the system is necessary to correlate the response time of each system to precipitation. Highly transmissive layers are necessary to accomplish this correlation. In the case of composite top liners, the $L R$ will require some calibration until a steady-state condition is attained. This is due to the longer migration time for leakage through the composite liner and, in fact, the delay until steady-state leakage is obtained. Upon attaining steady-state conditions for which reliable correlations between leakage and leachate removal can be developed, the $L R$ provides a measure of performance which reflects leakage as a function of source leachate, rather than as an absolute quantity.
4. $L R$ is best applied when the lag time for detection and measurement is minimized. Hence, the use of the most highly transmissive drainage layers for both leakage and leachate will provide the best data. Geonets serve as the best materials for that purpose. Similarly, the system with the fastest leakage time through the liner, namely geomembrane-only liners, will provide the easiest results to evaluate.

5. From the calculations illustrated, the best performance is provided for a composite liner. For the configurations assumed, an $L R$ of the order of $10^{5}$ is obtained for composite liners, $10^{3}$ for clay-only liners, and between $10^{2}$ and $10^{1}$ for geomembrane-only liners. To obtain the "best" design, the highest practical and feasible $L R$ should be targeted in the design process.

\section{References}

AKgüN H and Wallace RB (1993) Solid waste containment in double lined systems. J. Resour. Manag. Technol. 21 (3):137141

Bonaparte R, Giroud JP and Gross BA (1989) Rates of leakage through landfill liners. In: Proc. Geosynthetics '89 Conference, San Diego, California, Industrial Fabrics Association International (IFAI), Minneapolis, Minnesota, pp 18-29

Giroud JP and Bonaparte R (1989a) Leakage through liners constructed with geomembranes - Part I. Geomembrane liners. Geotextiles and Geomembranes 8:27-67

Giroud JP and BonaPARTE R (1989b) Leakage through liners constructed with geomembranes - Part II. Composite liners. Geotextiles and Geomembranes 8:71-111

LAMBE TW (1958) Compacted clay: engineering behavior. Journal of the Soil Mechanics and Foundations Division, ASCE Proceedings Paper 1655. 84 (SM4):24 pp

Mitchell JK, Hooper DR and Campanella RG (1965) Permeability of compacted clay. Journal of the Soil Mechanics and Foundations Division, ASCE. 91 (SM4): pp 41-65 